\title{
Modelling an experimental methane fuel processor
}

\author{
Shi-Tin Lin ${ }^{\text {a, }}$ Yih-Hang Chen ${ }^{\text {a }}$, Cheng-Ching $\mathrm{Yu}^{\mathrm{a}, *}$, \\ Yen-Chun Liu ${ }^{\mathrm{b}}$, Chiou-Hwang Lee ${ }^{\mathrm{b}}$ \\ ${ }^{a}$ Department of Chemical Engineering, National Taiwan University, Taipei 106-17, Taiwan \\ ${ }^{\mathrm{b}}$ Union Chemical Lab., Industrial Technology Research Institute, Hsinchu 300, Taiwan
}

Received in revised form 1 November 2004; accepted 25 January 2005

Available online 16 March 2005

\begin{abstract}
Steady-state models are developed to describe an experimental methane fuel processor that is intended to provide hydrogen for a fuel cell system for power generation $(2-3 \mathrm{~kW})$. First-principle reactor models are constructed to describe a series of reactions, i.e., steam and autothermal reforming (SR/ATR), high- and low-temperature water-gas shift (HTS/LTS) reactions and preferential oxidation (PROX) reactions, at different sectors of the reactor system for methane reforming as well as gas cleaning. The pre-exponential factors of the rate constants are adjusted to fit the experimental data and the resultant reactor model provides a reasonably good description of steady-state behaviour. Next, sensitivity analyses are performed to locate the optimum operating point of the fuel processor. The objective function of the optimization is fuel processor efficiency. The dominating optimization variables include: the ratios of water and oxygen to the hydrocarbon feed to the autothermal reforming reactor and the inlet temperature of the reactor. The results indicate that further improvement in fuel processor efficiency can be made with a reliable process model.
\end{abstract}

(C) 2005 Elsevier B.V. All rights reserved.

Keywords: Polymer electrolyte fuel cell; Fuel processor; Optimization; Anthermal reforming; Steam reforming; Preferential oxidation

\section{Introduction}

Fuel cell systems have received a great deal of attention in recent years because of their competitive efficiency and reduced emissions [1]. Fuel cell systems can be used in stationary or mobile applications. The polymer electrolyte membrane fuel cell (PEMFC) is attracting much attention; it uses either pure hydrogen or a hydrogen-rich gas mixture for power generation. Because of the difficulty associated with hydrogen storage [2], a reformer is often employed to convert hydrocarbons to hydrogen-rich synthesis gas ('syngas'). The syngas leaving out of the reformer usually contains hydrogen, carbon dioxide, water vapour, unconverted fuel and carbon monoxide (CO). Because of stringent limitation on the carbon monoxide concentration in the PEMFC [2], a series of CO-removing steps, such as the water-gas shift reaction and the preferential oxidation reaction, are

\footnotetext{
* Corresponding author. Tel.: +886 23365 1759; fax: +886 223623040.

E-mail address: ccyu@ntu.edu.tw (C.-C. Yu).
}

adopted to keep CO concentration below 100 ppm before entering the fuel cell. A reformer and several CO-removing reactors constitute a fuel processor. The fuel for the fuel processor will vary with different applications. It may be a liquid fuel such as methanol, gasoline and diesel for transportation systems, or natural gas or propane for stationary systems [1]. Options for converting fuels to hydrogen-rich syngas in the reformer include: steam reforming (SR) which uses fuel and water as feed; partial oxidation (POX) which uses fuel and oxygen as feed; autothermal reforming (ATR) which uses fuel, water and oxygen as feed, i.e., a combination of the endothermic SR reaction and the exothermic POX reaction [3].

Reviews on various aspects of fuel processing can be found in [4-7]. Research emphasis is still placed upon the reforming of hydrocarbon fuels. Reaction kinetics and reactor models have also been studied in [8-10]. A comparison of the efficiency for different fuels has been explored in [1], while simulation and reactor performance analyses have been examined in [3,10-12]. Relationships between thermodynamic 
properties and the expected performance of fuel processors have been presented in $[13,14]$.

This study presents a systematic approach towards the development and validation of a model for an experimental fuel process. First, the necessary experimental steps are performed. Then, a steady-state model is established and the kinetics parameters are adjusted to provide a description of the system behaviour. Finally, a sensitivity analysis is performed to determine the optimum operating conditions for improved efficiency.

\section{Experimental}

An experimental fuel processor was designed and installed in the facility of the Union Chemical Laboratory (UCL) of the Industrial Technology Research Institute (ITRI). The en- tire fuel processor set-up is composed of several reactors, heat-exchangers and a burner. A detailed drawing of the system with methane, water and oxygen as feed is presented in Fig. 1. The various feeds enter the system at room temperature and their individual flow rates can be adjusted. The mixed feed first passes through a heat-exchanger, the temperature of which increases slightly. Next, the feed passes through a pipe on the top of the reformer, which is coiled down in the outside, and then enters the reformer. A burner is placed under the reformer. It also uses methane as fuel and supplies heat directly to the reformer for pre-heating and reaction purposes. The reformer is made of stainless steel 304 that has a good heat-transfer capability. A honeycomb catalyst carrier is placed inside the reformer and the catalyst is coated on a ceramic carrier. The catalyst was developed by UCL of ITRI and is a $\mathrm{Ru} / \mathrm{CeO}_{2}-\mathrm{ZrO}_{2}$ catalyst. The reformer and burner are wrapped together in insulation mate-

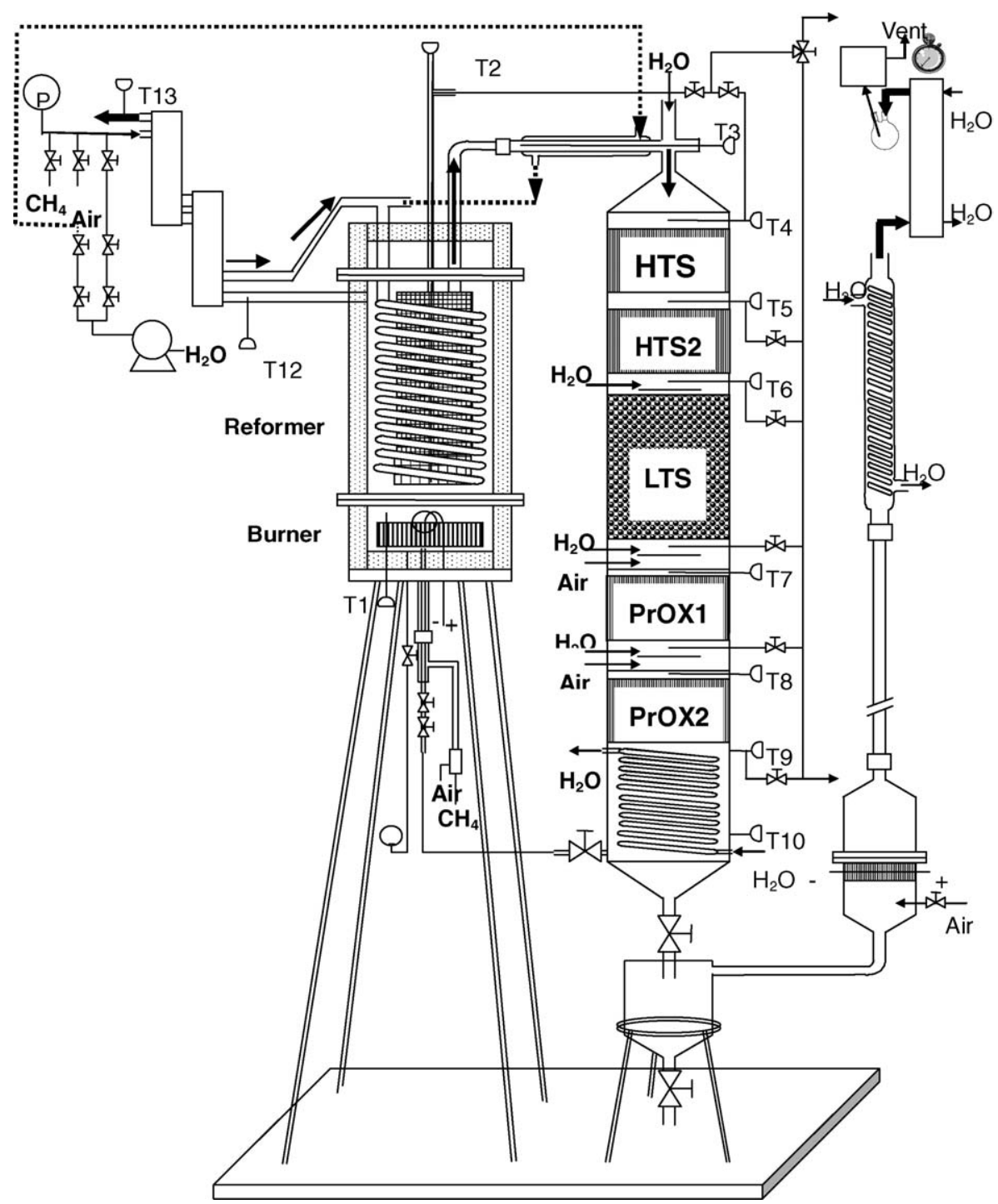

Fig. 1. Detail drawing of experimental fuel processor: T1, temperature of burner; T2, reformer inlet temperature; T3, reformer outlet temperature; T4, HTS1 inlet temperature; T5, HTS2 inlet temperature; T6, LTS inlet temperaturel; T7, PROX1 inlet temperature; T8, PROX2 inlet temperature. 
rials to prevent heat loss. The reactor effluent exits out from the top of the reformer and is further processed in a series of water-gas shift reactors and preferential oxidation reactors. The hot reformer effluent is cooled down by means of a heat-exchanger and direct water injection before entering the water-gas shift reactors. The temperatures of the water-gas shift reactors are arranged in decreasing order, i.e., water injection between reactors is devised to cool down the syngas. There are two high-temperature water-gas shift reactors (HTS1 and HTS2) and one low-temperature water-gas shift reactor (LTS). The operating temperature is between 300 and $400{ }^{\circ} \mathrm{C}$ for the HTSs, which contain a Pt/mixed-oxide catalyst that has been developed by UCL of ITRI and is coated on honeycomb carriers. The operating temperature of the LTS is between 190 and $250{ }^{\circ} \mathrm{C}$ and a commercial $\mathrm{Cu}-\mathrm{ZnO} / \mathrm{Al}_{2} \mathrm{O}_{3}$ catalyst is used. Oxygen is introduced directly before the syngas enters the preferential oxidation reactors (PROX). The reactions are promoted by a catalyst that has been prepared by UCL of ITRI and contains $3 \mathrm{wt} . \% \mathrm{Pt}$.

The objectives of the experimental set-up are:

(i) to test the reactivity and property of the catalysts developed by UCL of ITRI;

(ii) to obtain operating parameters to achieve the desired hydrogen flow rate and carbon monoxide concentration;

(iii) to compare the efficiencies of the different reaction pathways (autothermal reforming and steam reforming).

The experiment is operated in three stages: (i) heat-up, (ii) autothermal reforming, (iii) steam reforming. In the first 5 min, methane and air (oxygen) is fed into the reformer to carry out the combustion reaction and a large quantity of fuel is added to the burner to heat up the catalyst and the monolith support of the reformer. The purpose of this stage is to heat the reformer to the reaction temperature. The next step is to add water and the reformer follows the autothermal reforming (ATR) pathway. A suitable amount of fuel is added to maintain the reformer inlet temperature at about $667^{\circ} \mathrm{C}$. Finally, the air feed is stopped after $3.5 \mathrm{~h}$ with only methane and water as feeds. This implies that because of a higher operating temperature as well as strong exothermic reaction, the amount of fuel fed to the burner is larger than that required in the pathway. The results of typical experimental runs are given in Figs. 2-4. The fuel flow rates and temperatures at the inlet and the outlet of the reformer at the ATR and SR stages are shown in Fig. 2A and B, respectively. The temperature profiles for different sectors of the fuel processor are given in Fig. 3, and the concentration profiles for $\mathrm{CO}$, hydrogen and methane conversion in Fig. 4.

\section{Steady-state modelling of fuel processor}

\subsection{Description of system}

The general structure of the experimental fuel processor consists of two major parts. The first part is the reforming unit
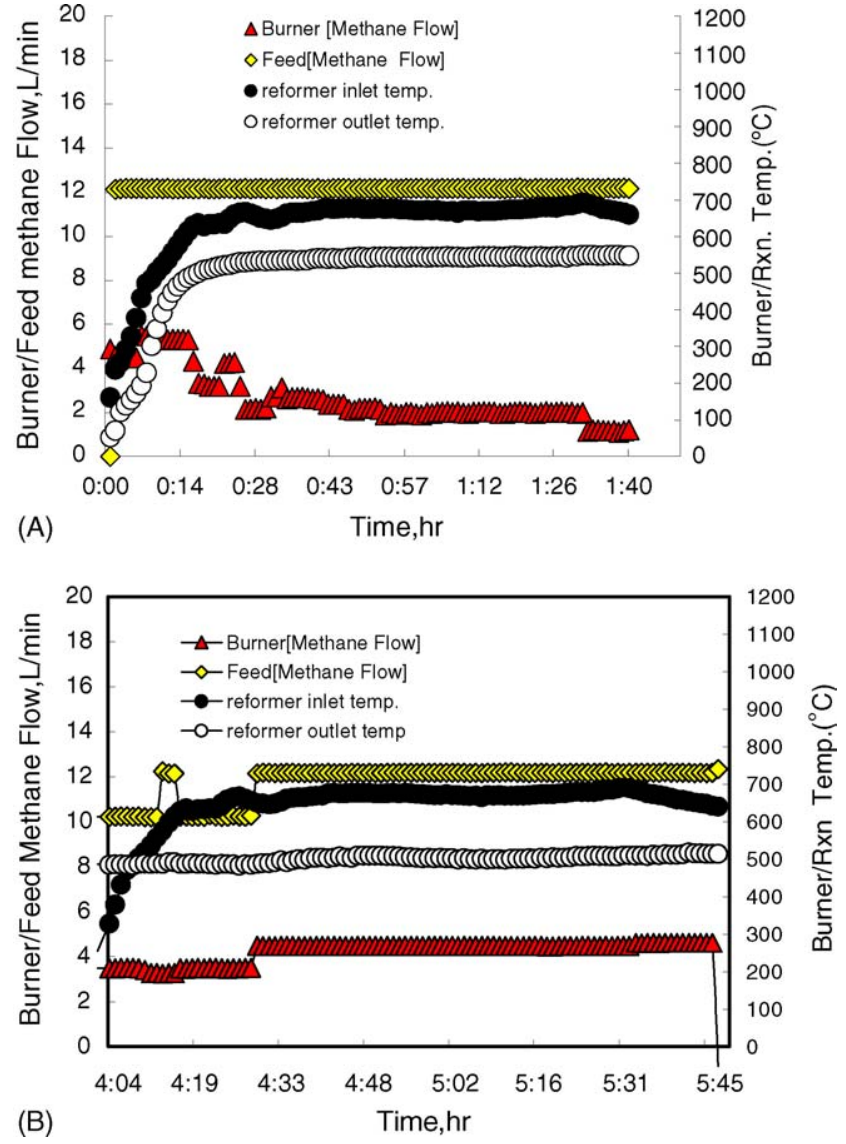

Fig. 2. Feed $\mathrm{CH}_{4}$ flow rate (reformer and burner), reformer inlet and outlet temperature at: (A) start-up and ATR pathway stages and (B) SR pathway stage.

and includes a reformer, a heat-exchanger and a burner in a heat-integrated framework, as shown in Fig. 6. The second part is the gas-cleaning unit, which is composed of reactors connected in series. Three of them carry out the water-gas shift reaction and two perform the preferential oxidation reaction. These reactors are lumped together in the modelling phase.

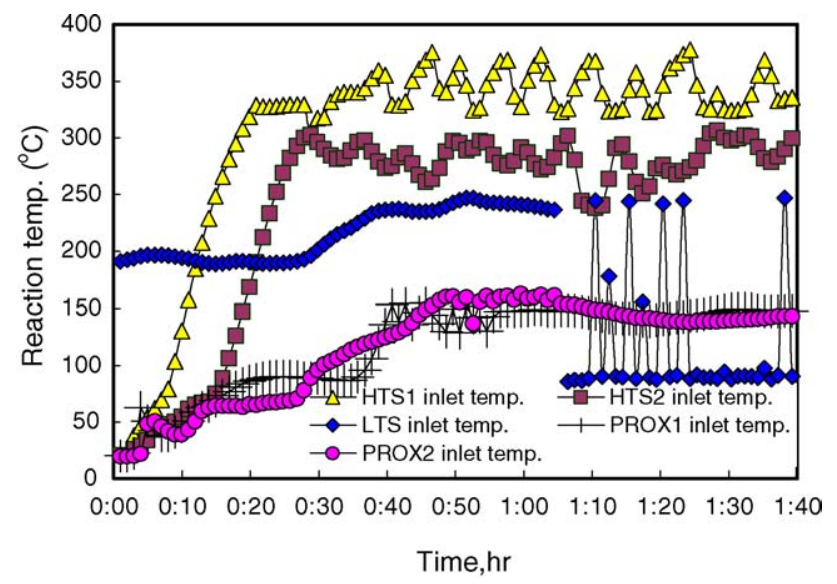

Fig. 3. Inlet temperatures of HTS1, HTS2, LTS, PROX1 and PROX2 at start-up and ATR pathway stage. 


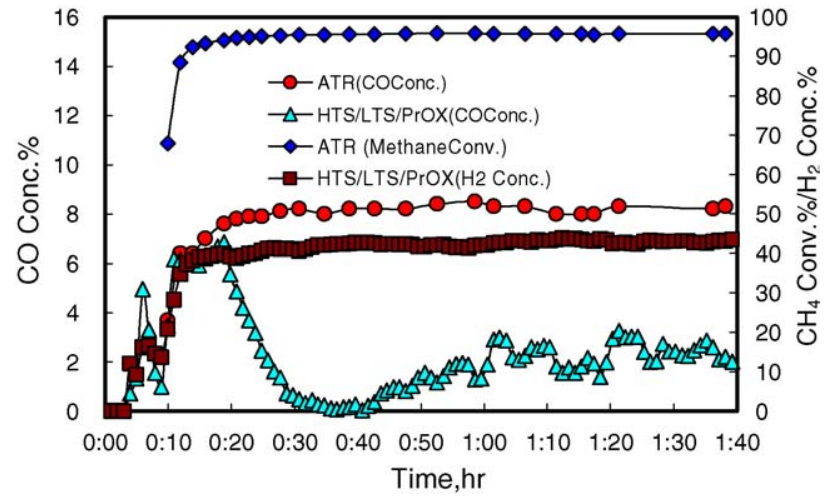

Fig. 4. $\mathrm{CO}$ concentration, methane conversion and $\mathrm{H}_{2}$ concentration at reformer outlet and various reactor outlets in gas-cleaning unit.

\subsection{Reactor modelling and corresponding reaction kinetics}

In order to simplify the numerical calculation, we assume a plug flow reactor (PFR) and a one-dimensional (in the axial direction) homogenous reactor model for the materials and energy balances. The steady-state changes in the molar flow rate of component $i\left(F_{i}\right)$ and temperature $(T)$ down the length of the PFR are calculated by numerical integration of ordinary differential equations. The independent variable is the reactor catalyst weight $W$, with the limits of integration between $W=0$ and $W=W_{\text {cat }}$. The equations describing the reformer can be expressed as follows:

$$
\begin{aligned}
\frac{\mathrm{d} F_{i}}{\mathrm{~d} W} & =\sum_{j} v_{j i} r_{i} \\
\frac{\mathrm{d} T}{\mathrm{~d} W} & =\frac{\sum_{j}\left(-\Delta H_{298 j}\right) r_{j}+4 U\left(T-T_{\mathrm{W}}\right) / \rho D_{\mathrm{I}}}{\sum_{i} F_{i} C_{\mathrm{P} i}}
\end{aligned}
$$

where $F_{i}$ is the molar flow rate of component $i$ at the axial position; $W$ the catalyst weight; $r_{j}$ the rate of reaction $j ; \rho_{j i}$ the stoichiometric coefficient of component $i$ for the reaction $j ; T$ and $T_{\mathrm{W}}$ the reaction temperature and metal wall temperature, respectively; $\Delta H_{298 j}$ the heat of reaction for reaction $j$; $\mathrm{U}$ the heat-transfer coefficient; $D_{\mathrm{I}}$ the inner-diameter of the reactor; $C_{\mathrm{P} i}$ the heat capacity of component $i ; \rho$ is the density of the catalyst. This is a heated PFR with heat transferred from the metal wall to the reactor. Because an outer coil is placed to heat up the reactant, the temperature of the reactor wall is modelled as:

$k_{\text {cond }} \frac{\mathrm{d} T}{\mathrm{~d} W}=4 U\left(T-T_{\mathrm{W}}\right) / \rho D_{\mathrm{I}}+4 U\left(T_{\mathrm{A}}-T_{\mathrm{W}}\right) / \rho D_{\mathrm{O}}$

where $k_{\text {cond }}$ is the heat conductivity of the reactor wall; $T_{\mathrm{A}}$ the temperature of the pipe that is coiled down the outside of the reactor, and $D_{\mathrm{O}}$ is the outer-diameter of the reformer. Note that, similar models (Eqs. (1) and (2)) are employed for the water-gas shift reactors and preferential oxidation reactors, but adiabatic operation is assumed.

The reactions taking place in the reformer are:

$$
\begin{aligned}
& r_{1}: \mathrm{CH}_{4}+\mathrm{H}_{2} \mathrm{O} \Leftrightarrow \mathrm{CO}+3 \mathrm{H}_{2}, \\
& \Delta H_{298}=206\left(\mathrm{~kJ} \mathrm{~mol}^{-1}\right) \\
& r_{2}: \mathrm{CO}+\mathrm{H}_{2} \mathrm{O} \Leftrightarrow \mathrm{CO}_{2}+\mathrm{H}_{2}, \\
& \Delta H_{298}=-41.2\left(\mathrm{~kJ} \mathrm{~mol}^{-1}\right) \\
& r_{3}: \mathrm{CH}_{4}+2 \mathrm{H}_{2} \Leftrightarrow \mathrm{CO}_{2}+2 \mathrm{H}_{2} \mathrm{O}, \\
& \Delta H_{298}=-810\left(\mathrm{~kJ} \mathrm{~mol}^{-1}\right)
\end{aligned}
$$

Here, it is assumed that carbon formation and carbon reforming can be neglected [10]. For methane reforming, the kinetic expression of $\mathrm{Xu}$ and Froment [15-17] is used, Eqs. (4) and (5). For methane combustion over a supported Pt catalyst (Eq. (6)), the rate expression of Trimm and Lam [18] is adopted here. The kinetics of these reactions are listed in Table 1.

The reaction that takes place in the water-gas shift reactors is the same as Eq. (5) except that a different type of catalyst is used. The rate expression of Choi and Stenger [9] is used to model the reactor, i.e.,

$r_{\mathrm{WS}}=k_{\mathrm{WS}}\left(\frac{P_{\mathrm{CO}} P_{\mathrm{H}_{2} \mathrm{O}}-P_{\mathrm{H}_{2}} P_{\mathrm{CO}_{2}}}{K_{\mathrm{eq}}}\right)$

Generally, the carbon monoxide concentration out of the water-gas shift reactors is still too high, i.e., at a level that can be poisonous to the precious metal catalyst in the anode of the PEMFC. Typically, preferential oxidation is used to reduce the $\mathrm{CO}$ concentration down to the ppm level. In the PROX reaction, small amount of air (oxygen) is introduced to oxidize $\mathrm{CO}$ directly to form carbon dioxide. Note that, in addition to the oxidation of $\mathrm{CO}$, hydrogen is also oxidized in the same reactor:

$$
\mathrm{CO}+\frac{1}{2} \mathrm{O}_{2} \Rightarrow \mathrm{CO}_{2}, \quad \Delta H_{298 \mathrm{~K}}=-283\left(\mathrm{~kJ} \mathrm{~mol}^{-1}\right)
$$

Table 1

Rate expression for reactions in reformer

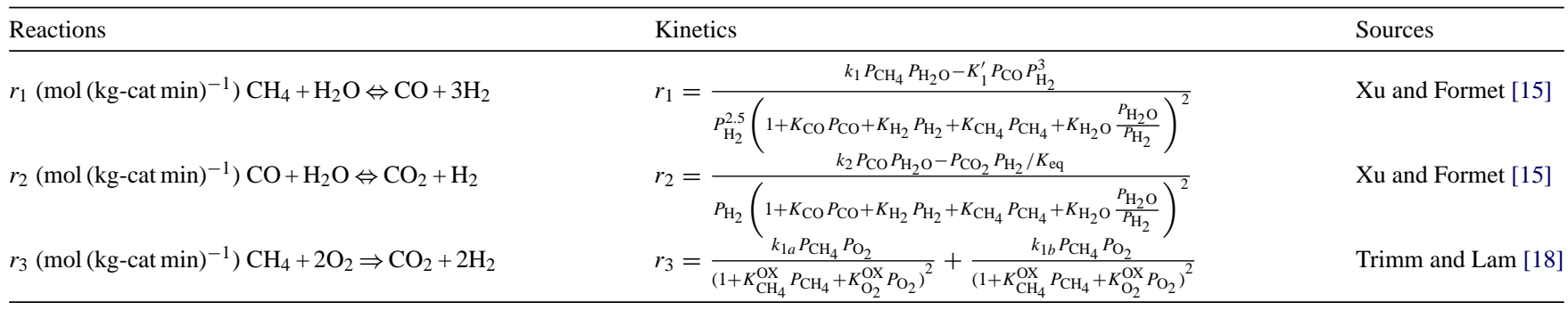




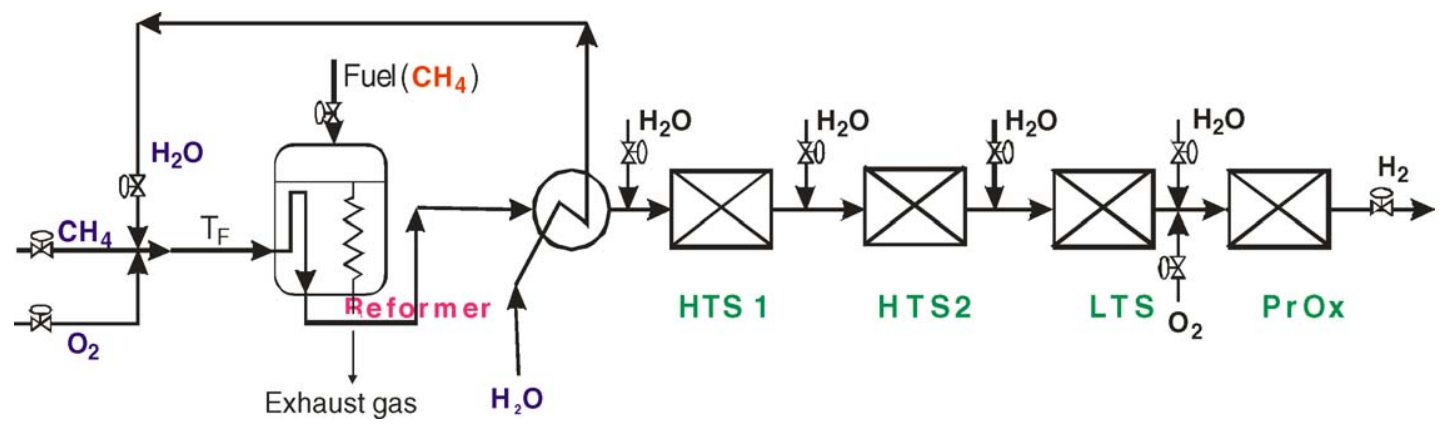

Fig. 5. Schematic of fuel processor for simulation.

$\mathrm{H}_{2}+\frac{1}{2} \mathrm{O}_{2} \Rightarrow \mathrm{CO}_{2}, \quad \Delta H_{298 \mathrm{~K}}=-243\left(\mathrm{~kJ} \mathrm{~mol}^{-1}\right)$

Only few papers address the simultaneous $\mathrm{H}_{2}$ oxidation along with $\mathrm{CO}$ oxidation for the PROX reaction. In this work, a constant selectivity is assumed [11]. The rate expression of Amphlett et al. [19] is used for CO oxidation and $40 \%$ selectivity is also assumed. Thus:

$r_{\text {prox }, 1}=k_{\text {prox }, 1} P_{\mathrm{CO}}$

$r_{\text {prox }, 2}=1.5 \times r_{\text {prox }, 1}$

\subsection{Cooling device models}

The reactor temperatures in the fuel processor are arranged in the descending order, so heat-exchanger and cooling devices are needed. Therefore, a heat-exchanger is installed between the reformer and the HTS1 and the syngas out of the reformer exchanges heat with the fresh liquid water feed, as shown schematically in Fig. 5. This is a standard exchanger and the exit temperature of the syngas ( $\left.T_{\text {exout }}\right)$ can be computed directly from the energy balance. This is followed by direct injection of water to cool down the syngas to the desired temperature. The amount of liquid water required $\left(F_{\mathrm{H}_{2} \mathrm{O}, i n j}\right)$ for cooling to $T_{\mathrm{HTS} 1}$ can be found by solving the following energy balance:

$$
\begin{aligned}
& \sum_{i} F_{i, \mathrm{ATR}, \text { out }} \int_{T_{\mathrm{exout}}}^{T_{\mathrm{HTS} 1}} C_{\mathrm{P} i} \mathrm{~d} T \\
& \quad+F_{\mathrm{H}_{2} \mathrm{O}, i n j}\left[C_{\mathrm{P}, \mathrm{H}_{2} \mathrm{O}}^{1}(373-298)+\Delta H_{\mathrm{H}_{2} \mathrm{O}}^{\mathrm{vap}}\right.
\end{aligned}
$$

$$
\left.+\int_{T_{373}}^{T_{\mathrm{HTS} 1}} C_{\mathrm{PH}_{2} \mathrm{O}} \mathrm{d} T\right]=0
$$

where $C_{\mathrm{P}, \mathrm{H}_{2} \mathrm{O}}^{1}$ and $C_{\mathrm{P}, \mathrm{H}_{2} \mathrm{O}}$ are the liquid and vapour phase heat capacity of water $\left(\mathrm{J} \mathrm{mol}^{-1} \mathrm{~K}^{-1}\right)$, respectively, and $\Delta H_{\mathrm{H}_{2} \mathrm{O}}^{\mathrm{vap}}$ represents the latent heat of water $\left(\mathrm{J} \mathrm{mol}^{-1}\right)$. Similarly, the water injected between the HTS1 and HTS2, HTS2 and LTS, and LTS and PROX can also be evaluated using Eq. (12).

\subsection{Data regression for steady-state model}

\subsubsection{Reforming unit}

The experiment is carried out in a sequential manner. It follows the ATR pathway initially and then switches to the SR reaction by cutting off the oxygen feed (Table 2). From the conversion data and the feed flow rate, the material balances can be obtained according to the reactions $\left(r_{1}-r_{3}\right.$ in Eqs. (4) to (6). The inlet and outlet flow rates for both reaction pathways are listed in Table 2.

Before addressing the details of the data fitting, several observations must be made. First, it is necessary to start from kinetics data regression for the SR because only two reactions are involved $\left(r_{1}-r_{2}\right.$ in Eqs. (4) and (5)). Second, the composition is more important than the temperature because the heat loss is not considered in the reactor models. Because the burner is not explicitly modelled, the metal wall temperature (Eq. (3)) in the reformer inlet $\left(T_{\mathrm{W}}(0)\right)$ is used to infer the effect of the burner; a simple model can be employed. In other words, the inlet metal wall temperature is taken as an adjustable parameter. In addition to $T_{\mathrm{W}}(0)$, the kinetics data from the literature are also modified to obtain better data

\begin{tabular}{|c|c|c|c|c|c|c|c|c|c|}
\hline $\begin{array}{l}\text { Reaction } \\
\text { pathway }\end{array}$ & $T\left({ }^{\circ} \mathrm{C}\right)$ & $\begin{array}{l}\mathrm{CH}_{4}{ }^{\mathrm{a}} \\
\left(\mathrm{mol} \mathrm{min}^{-1}\right)\end{array}$ & $\begin{array}{l}\mathrm{H}_{2} \mathrm{O} \\
\left(\mathrm{mol} \mathrm{min}^{-1}\right)\end{array}$ & $\begin{array}{l}\mathrm{CO}^{\mathrm{b}} \\
\left(\mathrm{mol} \mathrm{min}^{-1}\right)\end{array}$ & $\begin{array}{l}\mathrm{CO}_{2} \\
\left(\mathrm{~mol} \mathrm{~min}^{-1}\right)\end{array}$ & $\begin{array}{l}\mathrm{O}_{2}^{\mathrm{c}} \\
\left(\mathrm{mol} \min ^{-1}\right)\end{array}$ & $\begin{array}{l}\mathrm{H}_{2} \\
\left(\mathrm{~mol} \mathrm{~min}^{-1}\right)\end{array}$ & $\begin{array}{l}\mathrm{N}_{2} \\
\left(\mathrm{~mol} \mathrm{~min}^{-1}\right)\end{array}$ & $\begin{array}{l}\mathrm{CH}_{4} \text { burner } \\
\left(\mathrm{mol} \min ^{-1}\right)\end{array}$ \\
\hline ATR inlet & 667 & 0.48 & 0.883 & 0 & 0 & 0.22 & 0 & 0.83 & 0.08 \\
\hline ATR outlet & 557 & 0.0313 & 0.504 & 0.204 & 0.245 & 0.011 & 1.172 & 0.83 & - \\
\hline SR inlet & 867 & 0.48 & 1.44 & 0 & 0 & 0 & 0 & 0 & 0.18 \\
\hline SR outlet & 517 & 0.202 & 0.973 & 0.087 & 0.190 & 0 & 1.022 & 0 & - \\
\hline
\end{tabular}

Table 2

Inlet and outlet compositions and temperatures data for ATR and SR reforming

a $97 \%$ Conversions for ATR and $86 \%$ conversion for SR (dry basis).

b Outlet concentration of $8.2 \%$ for ATR and $5.8 \%$ for SR (dry basis).

c $\mathrm{O}_{2}$ conversion of $95 \%$. 
Table 3

Kinetic parameters from literature and from regression

\begin{tabular}{lll}
\hline $\begin{array}{l}\text { Pre-exponential factor } \\
\text { (rate constant) }\end{array}$ & Literature & Regression \\
\hline$r_{1}$ forward & $7.02 \times 10^{16}$ & $6.32 \times 10^{16}$ \\
$r_{1}$ reverse & $5.862 \times 10^{3}$ & $1.759 \times 10^{3}$ \\
$r_{2}$ forward & $3.258 \times 10^{7}$ & $2.77 \times 10^{6}$ \\
$r_{3}$ forward $a$ & $4.866 \times 10^{7}$ & $1.56 \times 10^{8}$ \\
$r_{3}$ forward $b$ & $4.092 \times 10^{7}$ & $1.31 \times 10^{8}$ \\
\hline
\end{tabular}

fitting. Typically, the pre-exponential factors are adjusted to match the experimental results [16] while keeping the activation energies and adsorption constants unchanged [10]. Hence, the data-fitting algorithm of the reformer has the following steps:

(i) Starting with the $\mathrm{SR}$ pathway, $T_{\mathrm{W}}(0)$ is changed to match the outlet temperature of SR and the pre-exponential factors of $r_{1}$ and $r_{2}$ (Eqs. (4) and (5)) are adjusted to match the outlet component flow rates.

(ii) While keeping the kinetics parameters of $r_{1}$ and $r_{2}$ fixed, $T_{\mathrm{W}}(0)$ and the pre-exponential factor of $r_{3}$ (Eq. (3)) are varied to match the outlet temperature and component flows for the ATR pathway.

(iii) $T_{\mathrm{W}}(0)$ is constrained by establishing a linear equation to relate $T_{\mathrm{W}}(0)$ with $T(0)$.

(iv) The kinetics parameters of $r_{1}$ and $r_{3}$ are modified so that the errors are of the same order of magnitude for the SR and ATR pathways.

The kinetics parameters of all three reactions from the literature and from the data regression are shown in Table 3. The results indicate that most of the regressed pre-exponential factors are quite close to the literature data and have the same activation energies and absorption constants. The relationship between $T_{\mathrm{W}}(0)$ and $T(0)$ can be expressed in ${ }^{\circ} \mathrm{C}$ as:

$T_{\mathrm{W}}(0)=1.65 \times T(0)-864$

The temperature and component flow rates along the axial position for the ATR and SR pathways are shown in Figs. 6 and 7, respectively. The outlet flow conditions predicted are roughly the same as the experimental data (see open circles in Figs. 6 and 7), but the outlet temperature predicted by the model is higher than the experimental data, especially in ATR pathway. This may be the result of heat loss or an inappropriate location for the thermocouple.

The composition and temperature profiles in Figs. 6 and 7 indicate that high inlet temperature leads to fast reaction, especially for $r_{1}$. This results in a rapid decrease in the reactor temperature and a fast increase in the yield of hydrogen, as can be seen in Figs. 6 and 7 for both ATR and SR pathways. For the ATR, the oxidation reaction $\left(r_{3}\right)$ leads to an increase in the reactor temperature, so the yield of hydrogen and the conversion of methane continue to improve towards the middle of the reactor, as shown in Fig. 6. On the other hand, most of the methane is converted very early in the PFR for the SR pathway (Fig. 7). The concentration of carbon dioxide increases rapidly initially for both ATR and SR pathways. For the SR pathway, a lower temperature towards the middle of the reactor favours $r_{2}$ (Eq. (5)), so the concentration of carbon dioxide decreases towards the reactor exit. For the ATR pathway, however, the concentration increases monotonically as a result of the temperature increase towards the end of the PFR.

\subsubsection{Gas-cleaning unit}

After setting up the steady-state reactor models for the reformer under different operations, a similar approach can be
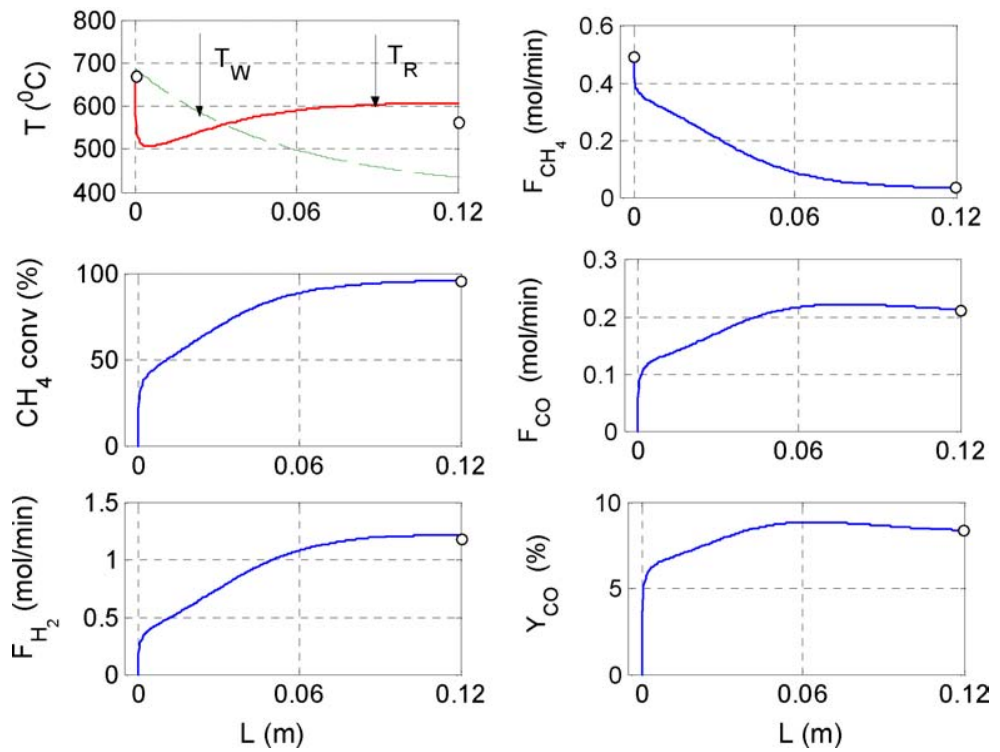

Fig. 6. Temperatures (metal wall and reactor), $\mathrm{CH}_{4}$ conversion, $\mathrm{CO}$ concentration and molar flow rates over axial position of ATR pathway (open circles indicate experimental results). 

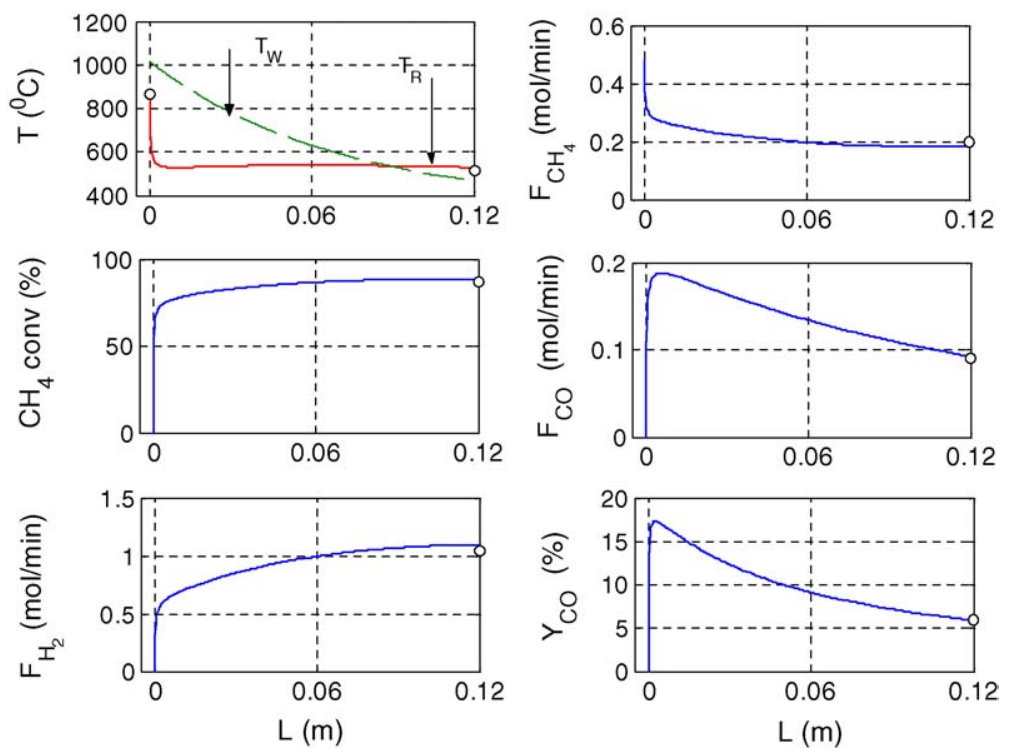

Fig. 7. Temperatures (metal wall and reactor), $\mathrm{CH}_{4}$ conversion, $\mathrm{CO}$ concentration and molar flow rates over axial position of SR pathway (open circles indicate experimental results).

Table 4

Experimental temperature, composition and kinetics parameters for water-gas shift reactors for ATR pathway

\begin{tabular}{|c|c|c|c|c|c|}
\hline Reactor & $T_{\mathrm{m}}\left({ }^{\circ} \mathrm{C}\right)$ & $\mathrm{CO}(\%$; dry basis $)$ & $\mathrm{H}_{2}(\%$; dry basis $)$ & Pre-exponential factor (literature [9]) & Pre-exponential factor (regression) \\
\hline HTS1 & 350 & $2.2-2.5$ & $44-46$ & $4.943 \times 10^{6}$ & $0.989 \times 10^{6}$ \\
\hline HTS2 & 320 & $1.5-1.7$ & $45-47$ & $4.943 \times 10^{6}$ & $0.989 \times 10^{6}$ \\
\hline LTS & 260 & $1.1-1.3$ & $48-50$ & $4.943 \times 10^{6}$ & $1.285 \times 10^{6}$ \\
\hline
\end{tabular}

applied to the gas-cleaning unit. The HTS1, HTS2, LTS and PROX reactors are arranged in series, so the regression can be carried out sequentially. Also note that all these reactors are assumed to be adiabatic. For the water-gas shift reaction (Eq. (5)) with different catalysts, Table 4 gives the experimental data for the ATR pathway. As for the reformer example, the pre-exponential factor (Eq. (7)) is adjusted for data-fitting for the HTS1 and HTS2 while keeping the activation energy and equilibrium constant. The procedure is repeated for the LTS. The results in Table 4 indicate that the pre-exponential factors from data regression are of the same order of magnitude as those reported in the literature.
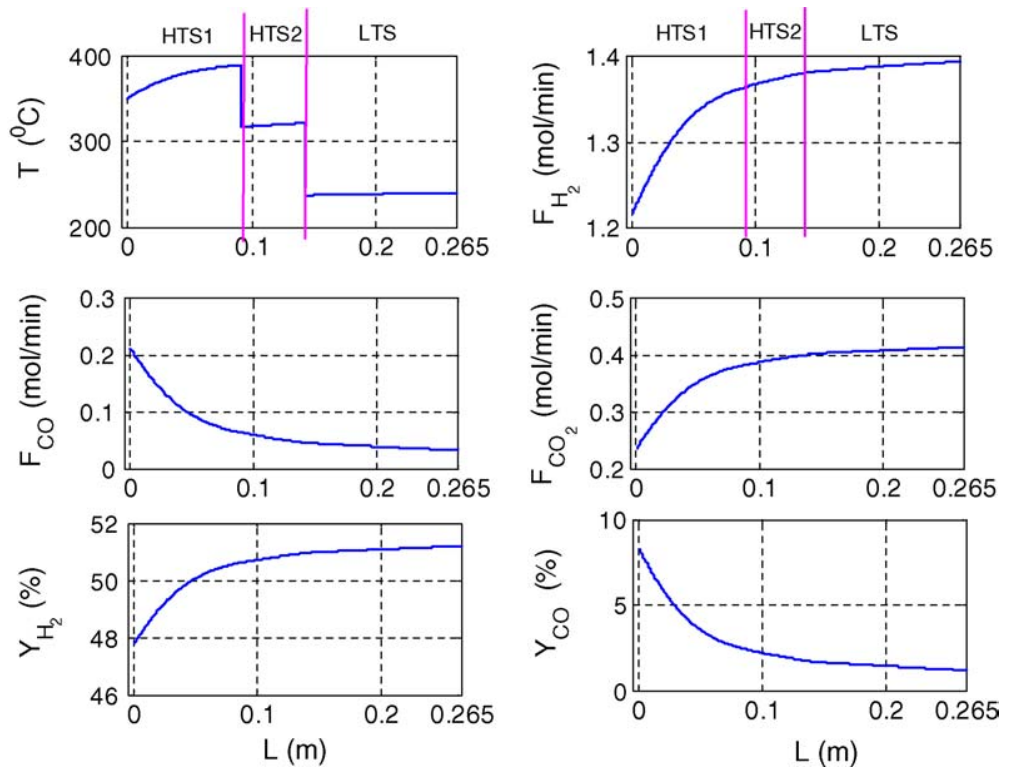

Fig. 8. Temperature, $\mathrm{CO}$ and $\mathrm{H}_{2}$ concentration and molar flow rate over reformer, HTS1, HTS2 and LTS reactors over axial position for ATR pathway. 

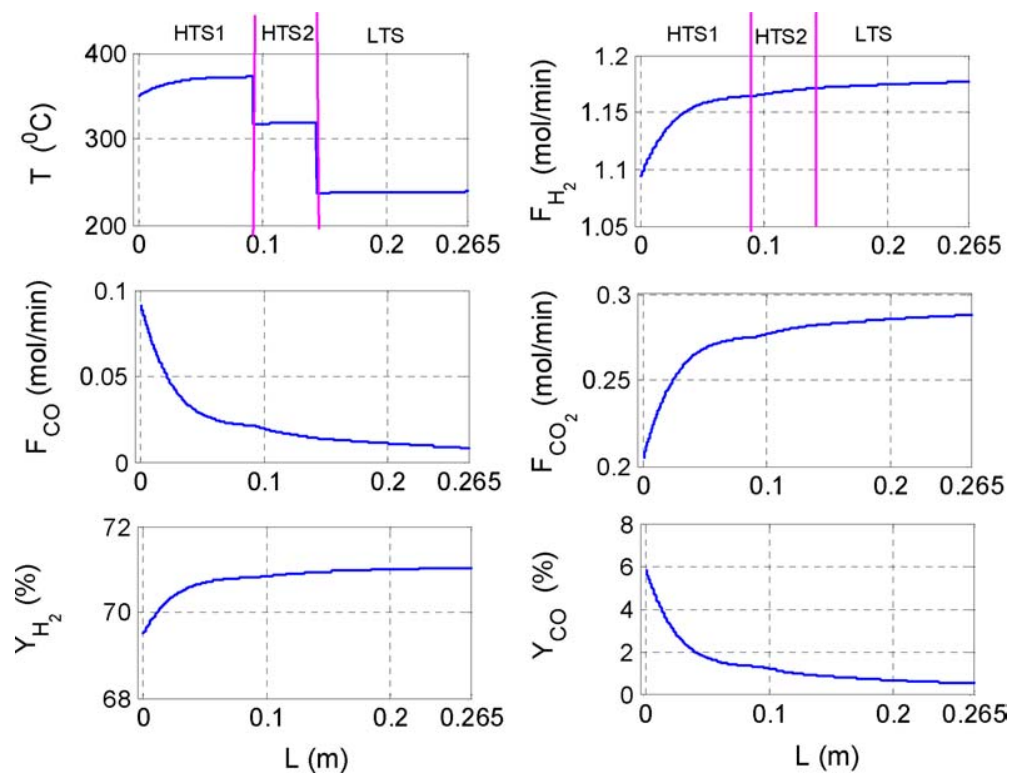

Fig. 9. Temperature, $\mathrm{CO}$ and $\mathrm{H}_{2}$ concentration and molar flow rate over reformer, HTS1, HTS2, and LTS reactors over axial position for SR pathway.

Steady-state simulation results for the water-gas shift reactions are given in Figs. 8 and 9. As a result of exothermic reaction (Eq. (5)), the reactor temperatures go up along the axial position for all three reactors. A significant temperature rise is observed for the HTS1, because of the large conversion of carbon monoxide, and this is true for both the ATR and the SR pathways. By comparison, the ATR pathway (Fig. 8) has a larger temperature increase (Fig. 9) because of its higher concentration of carbon monoxide in the reactor inlet. Finally, two PROX reactors are installed for the further consumption of carbon monoxide. Because the concentration out of the PROX is not quite stable, an average value of $40 \mathrm{ppm}$ has been taken for the ATR pathway to back-calculate the kinetics parameters. This completes the steady-state modelling of the entire fuel processor.

\section{Sensitivity analysis and optimization}

Once the steady-state model is available, it is possible to predict the behaviour of the experimental fuel processor. Design parameters such as process configuration, catalyst selection, reactor design and operating parameters will affect the performance of a fuel processor. Here, we are interested in the operational aspect of the experimental fuel processor and the operating parameters studied include the following:

(i) The inlet temperature of the reformer, $T_{\text {in }}$, is an important operating parameter. A high $T_{\text {in }}$ favours the endothermic steam reforming reaction (Eq. (4)) and this will result in an increase in the yield of hydrogen. There are disadvantages, however, in the form of higher energy input and higher $\mathrm{CO}$ concentration at the reactor effluent. (ii) The kinetics in Eqs. (4) and (5) indicate that a high waterto-carbon feed ratio favours $\mathrm{H}_{2}$ generation reactions, but it also requires more heat input from the burner.

(iii) An increase in the oxygen-to-carbon feed ratio favours the combustion reaction, Eq. (6), so it will lead to a higher reactor temperature and the endothermic steam reforming reaction (Eq. (4)) is favoured. Due to a larger share of the combustion reaction, less heat input is needed.

Efficiency is generally used to evaluate the performance of a fuel processor $[1,11,12]$, and is defined as:

Efficiency $(\mathrm{EFF} \%)=\frac{\mathrm{LHV} \text { of } \mathrm{H}_{2}}{\text { Heat input }+\mathrm{LHV} \text { of } \mathrm{CH}_{4}}$

where LHV is the lower heating value and 'heat input' is the heat supplied from the burner to the reformer.

\subsection{Effect of reformer inlet temperature $T_{\text {in }}$}

The effect of $T_{\text {in }}$ on the experimental fuel processor with the ATR and SR pathways, while keeping other operating parameters constant, is shown in Fig. 10. The arrows in Fig. 10 indicate the base case (experimental) operating point. As $T_{\text {in }}$ increases, the endothermic reaction (Eq. (4)) is favoured. This leads to better methane conversion and a higher hydrogen production rate in both the ATR and SR pathways, as shown in Fig. 10. At the same time, more $\mathrm{CO}$ is also produced (Eq. (4)) and this results in a heavier load on the gas-cleaning unit. The data in Fig. 10 also reveal that the SR pathway is more sensitive to changes in inlet temperature than the ATR pathway. As for efficiency, a higher $T_{\text {in }}$ implies a larger heat input along with a higher rate of hydrogen production. For the ATR pathway, a rather flat efficiency profile is observed and the optimum value is located at $T_{\mathrm{in}}=750^{\circ} \mathrm{C}$. The SR 


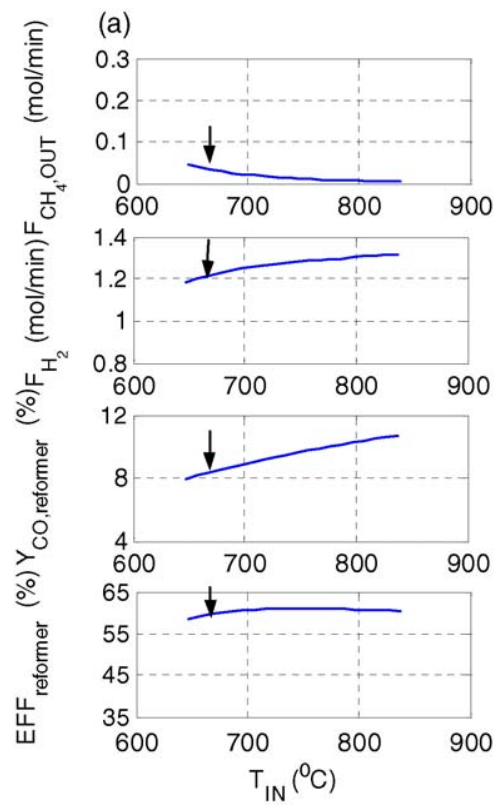

(b)
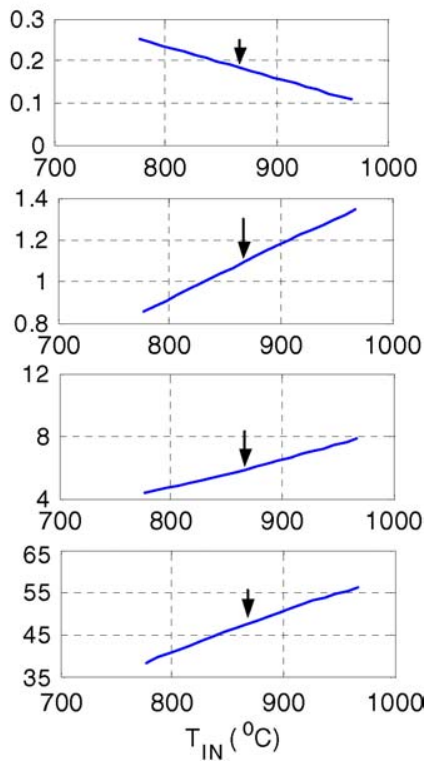

Fig. 10. Effects of reformer inlet temperature on $\mathrm{CH}_{4}$ conversion, $\mathrm{H}_{2}$ production rate, $\mathrm{CO}$ concentration and efficiency of reformer for: (A) ATR pathway and (B) SR pathway.

pathway, on the other hand, shows a significant increase in the efficiency as the result of a drastic increase in the hydrogen production rate.

\subsection{Effects of water-to-carbon feed ratio}

The effect of the $\mathrm{H}_{2} \mathrm{O}: \mathrm{CH}_{4}$ ratio is explored with a constant $\mathrm{CH}_{4}$ feed rate, as shown in Fig. 11. For the ATR pathway, an increase in the ratio favours the reforming and water-gas shift reactions (Eqs. (4) and (5)) because of excess water (in a relative sense). This leads to an initial increase $\left(\mathrm{H}_{2} \mathrm{O}: \mathrm{CH}_{4}<2.5\right)$ in the hydrogen yield followed by a decrease $\left(\mathrm{H}_{2} \mathrm{O}: \mathrm{CH}_{4}>2.5\right)$. The reason is that a further increase in the $\mathrm{H}_{2} \mathrm{O}: \mathrm{CH}_{4}$ ratio suppresses the combustion reaction (Eq. (6)) and, subsequently, lowers the reactor temperature. Thus, an almost decreasing trend in the efficiency is also observed as the ratio increases (the optimum is located at $\mathrm{H}_{2} \mathrm{O}: \mathrm{CH}_{4}=1.8$ ). The SR pathway, on the other hand,

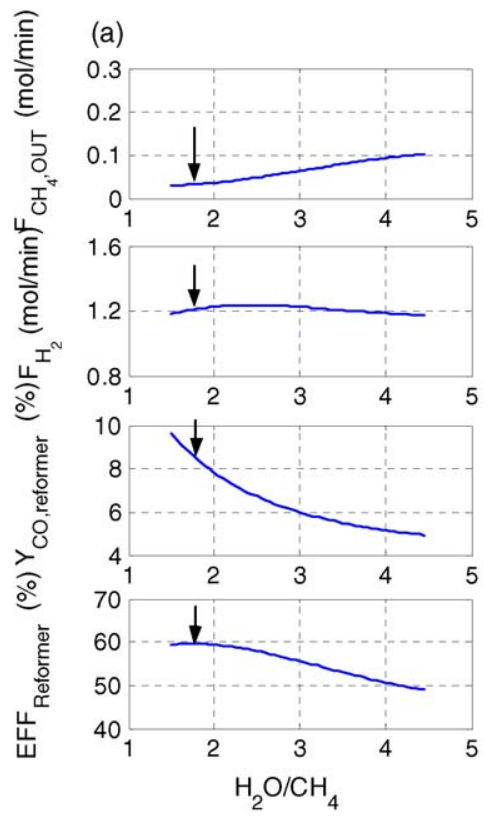

(b)
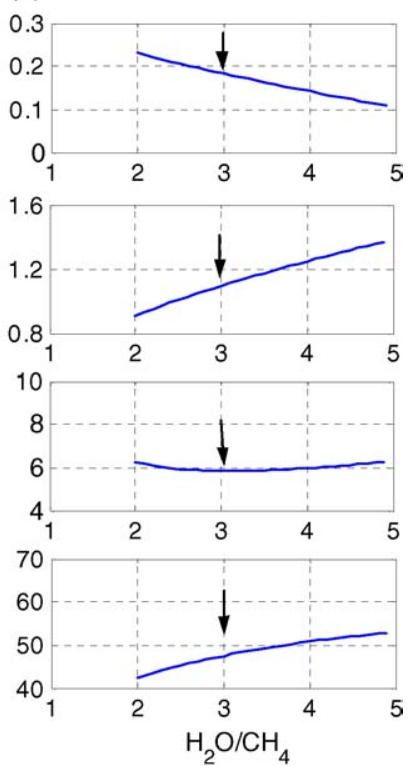

Fig. 11. Effects of $\mathrm{H}_{2} \mathrm{O}: \mathrm{CH}_{4}$ feed ratio on $\mathrm{CH}_{4}$ conversion, $\mathrm{H}_{2}$ production rate, $\mathrm{CO}$ concentration and efficiency of reformer for: (A) ATR pathway and (B) SR pathway. 

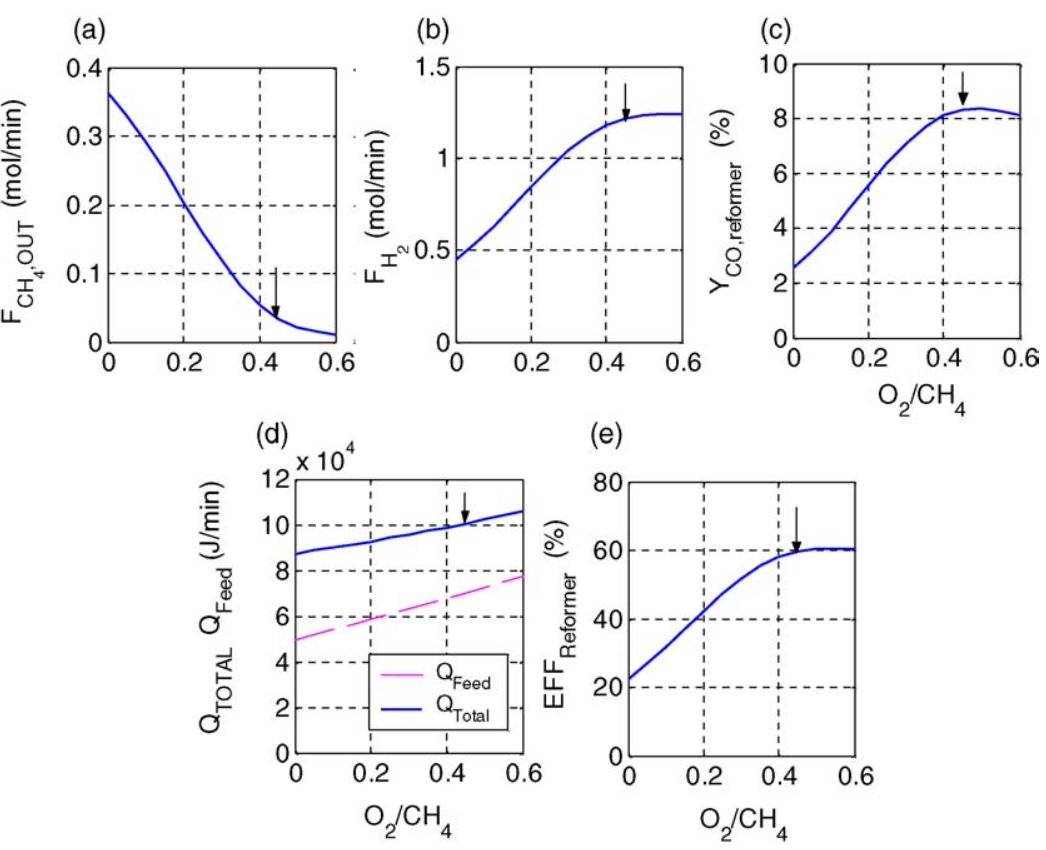

(e)

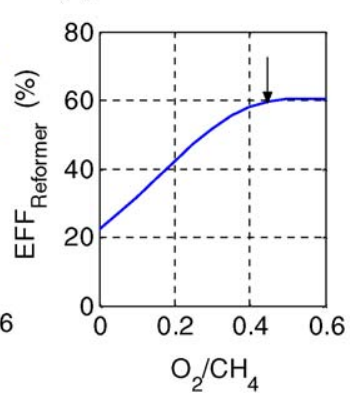

Fig. 12. Effects of $\mathrm{O}_{2}: \mathrm{CH}_{4}$ feed ratio on $\mathrm{CH}_{4}$ conversion, $\mathrm{H}_{2}$ production rate, $\mathrm{CO}$ concentration, energy supplied and efficiency of reformer for ATR pathway.

shows a more favourable trend for a high $\mathrm{H}_{2} \mathrm{O}: \mathrm{CH}_{4}$ ratio. The reason is quite clear, namely the combustion reaction is not involved.

\subsection{Effect of oxygen-to-carbon feed ratio}

The $\mathrm{O}_{2}: \mathrm{CH}_{4}$ ratio is also an important factor for the ATR pathway. The influence of this ratio with a constant $\mathrm{CH}_{4}$ feed flow rate. As the ratio increases, the rate of the combustion reaction (Eq. (6)) increases and consequently heats up the reactor. This leads to a higher hydrogen generation (Eq. (4)) and a higher $\mathrm{CO}$ concentration. As a result of the higher yield of hydrogen, the efficiency goes up as $\mathrm{O}_{2}: \mathrm{CH}_{4}$ ratio increases and it reaches a flat maximum at a ratio of $0.45-0.6$.

\subsection{Optimization of operating parameters}

Before determining the optimization stage, the base case operating condition (i.e., the arrows in Figs. 10-12) is examined. The ATR pathway has a $\mathrm{H}_{2}$ yield of $1.28 \mathrm{~mol} \mathrm{~min}^{-1}$, a CO concentration of $40 \mathrm{ppm}$ and an efficiency of $66 \%$. By contrast, the $\mathrm{SR}$ base case gives a $\mathrm{H}_{2}$ yield of $1.18 \mathrm{~mol} \mathrm{~min}^{-1}$, a CO concentration of $30 \mathrm{ppm}$ and an efficiency of $51 \%$. This corresponds to a power generation of $2-2.2 \mathrm{~kW}$. Because the ATR reaction has a higher efficiency and a larger hydrogen yield with a lower inlet temperature, this pathway is chosen for subsequent optimization. Also note that, actually, the base case operating condition of the ATR is quite close to the optimum, as can be seen from Figs. 10-12.

Because the aim is to find a long-term operating condition with less expensive construction materials, several constraints are imposed. First, the reformer inlet temperature is restricted to $717^{\circ} \mathrm{C}$ (a bit lower than $720^{\circ} \mathrm{C}$ ) to prevent unnecessary breakdown over a long period of operation (the construction material for the reformer is stainless steel 304). Second, the CO concentration in the syngas out of the fuel processor is limited to $45 \mathrm{ppm}$. Once these constraints are in place, the optimization variables include $\mathrm{O}_{2}: \mathrm{CH}_{4}$ feed ratio, $\mathrm{H}_{2} \mathrm{O}: \mathrm{CH}_{4}$ feed ratio and $T_{\text {in }}$. The objective is to maximize the efficiency by adjusting these three optimization variables simultaneously. The results show that the optimum operating conditions are: $\mathrm{H}_{2} \mathrm{O}: \mathrm{CH}_{4}=1.45$, $\mathrm{O}_{2}: \mathrm{CH}_{4}=0.45$ and $T_{\mathrm{in}}=717^{\circ} \mathrm{C}$ with a hydrogen production rate of $1.38 \mathrm{~mol} \mathrm{~min}^{-1}$. This corresponds to an efficiency of $68.4 \%$. This constrained optimization procedure leads to a slight improvement in the efficiency of the fuel processor, viz., 2.5\%. This is because the base case operating condition of the ATR is quite close to the optimum, as can be seen in Figs. 10-12.

\section{Conclusions}

Experimental runs have been performed on a methane fuel processor from start-up, to autothermal reforming, then to steam reforming. Next, steady-state models have been established to describe the reforming and gas-cleaning units. A systematic procedure is devised to adjust the kinetic parameters such that a reasonable behaviour description can be obtained. Based on the model, sensitivity analysis is performed and the optimum operating condition can be determined. The results of the constrained optimization indicate that further improvement can be achieved for the experimental fuel processor. 


\section{References}

[1] S. Ahmed, M. Krumpelt, Int. J. Hydrogen Energy 26 (2001) 291-301.

[2] Fuel Cell Handbook, EG\&G Services Parsons Inc., Science Applications International Corporation, 2000.

[3] A. Ersoz, H. Olgun, S. Ozdogan, C. Gungor, F. Akgun, M. Týrýs, J. Power Sources 118 (2003) 384-392.

[4] J. Larminie, A.L. Dicks, Fuel Cell Systems Explained, Wiley, New York, 2000.

[5] J.H. Hirschenhofer, D.B. Stauffer, R.R. Engleman, M.G. Klett, Fuel Cell Handbook, forth ed., DOE/FETC-99/1076, US Department of Energy, Federal Energy Technology Center, Morgantown, WV, November, 1998.

[6] C. Song, Catal. Today 77 (2002) 17-49.

[7] R.J. Farrauto, R.M. Heck, Catal. Today 55 (2000) 179-187.

[8] Y. Choi, H.G. Stenger, J. Power Sources 129 (2004) 246254.
[9] Y. Choi, H.G. Stenger, J. Power Sources 124 (2003) 432-439.

[10] C.R.H. de Smet, M.H.J. de Croon, M.R.J. Berger, G.B. Marin, J.C. Schouten, Chem. Eng. Sci. 56 (2001) 4849-4861.

[11] E.D. Doss, R. Kumar, R.K. Ahluwalia, M. Krumpelt, J. Power Sources 102 (2001) 1-15.

[12] J.R. Lattner, M.P. Harold, Int. J. Hydrogen Energy 29 (2004) 393-417.

[13] J. Cunha, J.L.T. Azevedo, J. Power Sources 86 (2000) 515-522.

[14] O. Wokrz, K.P. Jakckel, T. Richter, A. Wolf, Chem. Eng. Sci. 56 (2001) 029-033.

[15] J. Xu, G.F. Froment, AIChE J. 35 (1989) 88-96.

[16] J.R. Lattner, M.P. Harold, Int. J. Hydrogen Energy 29 (2004) 393-417.

[17] M. Pacheco, J. Sira, J. Kopasz, Appl. Catal. A: Gen. 250 (2003) 161-175.

[18] D.L. Trimm, C.W. Lam, Chem. Eng. Sci. 35 (1980) 1405-1413.

[19] J.C. Amphlett, R.F. Mann, B.A. Peppley, Int. J. Hydrogen Energy 21 (8) (1996) 673-678. 